\title{
Resultados dos testes de campo para o sistema Brasileiro de TV Digital ISDTV
}

\author{
Danillo Ono, Fujio Yamada e Cristiano Akamine
}

\begin{abstract}
Resumo- Em julho de 2006, o governo brasileiro estabeleceu o sistema ISDTV como padrão de radiodifusão terrestre para TV digital no Brasil. As principais inovações foram a adoção do padrão de compressão de vídeo H264/AVC para toda a transmissão e o uso do middleware desenvolvido no Brasil. Este trabalho apresenta um estudo do sistema de transmissão do ISDTV e resultados de testes de campo realizados em São Paulo para avaliação do sistema. Os procedimentos do teste de campo incluem a captura e armazenamento dos sinais de RF, utilizando um sistema de captura de RF, e posterior análise dos dados em laboratório.
\end{abstract}

Palavras-chave - TV Digital, ISDTV, Testes de campo, Captura de RF, Recepção Portátil.

\begin{abstract}
In July, 2006, the Brazilian Government established, the ISDTV as standard for digital terrestrial broadcasting TV in Brazil. The main innovations of ISDTV were the adoption of H264/AVC video coding in all transmissions layers and the use of a middleware developed in Brazil. This work presents a summary of the new modulation scheme (ISDTV) and the results of a field test carried out to evaluate the new system performance, in Sao Paulo. The field test procedure included the capture and record of the RF signal, using a "RF capture" equipment and analyzing the results in the laboratory.
\end{abstract}

Keywords - TV Digital, ISDTV, Field Tests, RF Capture, Portable reception.

\section{INTRODUÇÃO}

No Brasil, as principais cidades estão localizadas perto ou entre a costa e a serra, portanto, a maior parcela da população, vive perto ou entre a costa e as montanhas. As conseqüências desta geografia acidentada e montanhosa, na transmissão de sinais de TV aberta, exigem o uso de técnicas de modulação robustas, garantindo assim a qualidade do sistema de comunicação.

A TV aberta no Brasil tem grande importância como meio de comunicação em massa, uma vez que segundo levantamento da Agência Nacional de Telecomunicações (ANATEL), apenas $9,5 \%$ da população possui acesso a algum tipo de TV paga, ou seja, todos os 90,5\% restantes da população recebem o sinal de TV aberta, através da utilização de uma antena receptora, seja ela interna ou externa.

Em julho de 2006, o governo brasileiro estabeleceu como padrão para transmissão de TV Digital no Brasil, o ISDTV (International System for Digital TV), que utiliza um sistema baseado na modulação BST-OFDM (Band Segmented Transmission - Orthogonal Frequency Division Multiplexing), similar ao utilizado pelo padrão japonês (ISDB-T) [1].

O sistema ISDTV é composto por sete normas que

Danillo Ono, Fujio Yamada e Cristiano Akamine, Escola de Engenharia Universidade Presbiteriana Mackenzie, São Paulo, Brasil, E-mails: d.ono@mackenzie.br, akamine@mackenzie.br e fyamada @ mackenzie.br. especificam o sistema de transmissão, codificação fonte, multiplexação, terminal de acesso, direitos autorais, codificação de dados e canal de retorno.

Este padrão de modulação, divide a banda de $6 \mathrm{MHz}$ do canal de TV em 14 segmentos de $428 \mathrm{kHz}$ cada, o que permite a transmissão simultânea de até 13 segmentos, divididos em até 3 camadas, as quais possuem diferentes graus de robustez, dependendo da aplicação.

As principais inovações do ISDTV foram a adoção do sistema de compressão de vídeo H264/AVC para toda a transmissão, ao invés da utilização do MPEG-2 e o uso do middleware desenvolvido por brasileiros.

Para a análise do desempenho do novo sistema ISDTV, foi utilizado um transmissor digital de $1 \mathrm{~kW}$, transmitindo no canal 24 UHF (533 MHz) na cidade de São Paulo, onde existem mais de 18 milhões de pessoas.

Os equipamentos foram ajustados para permitir a transmissão no modo " $12+1$ ": 12 segmentos transmitindo um sinal HDTV para receptores fixos e 1 segmento destinado à transmissão para receptores móvel-portáteis.

Os pontos de recepção, setenta e dois no total, foram escolhidos através de circunferências traçadas com o centro na estação transmissora, com distâncias de 2, 5 e $10 \mathrm{~km}$ da torre.

Os procedimentos do teste de campo incluíram a análise subjetiva da qualidade de áudio e vídeo nos pontos de medição e a captura e armazenamento dos sinais de RF, para posterior análise dos dados em laboratório.

Este artigo apresenta os resultados dos testes de campo realizados na cidade de São Paulo utilizando o sistema ISDTV.

Na Seção II será descrito o sistema ISDTV, considerando os aspectos referentes à modulação. Os parâmetros de medição, equipamentos de transmissão e recepção serão descritos na Seção III. A Seção IV apresenta a análise dos resultados dos testes e por fim, na Seção $\mathrm{V}$ as conclusões.

\section{O SISTEMA ISDTV}

O sistema ISDTV, utiliza a modulação BST-OFDM, que consiste em dividir a banda de $6 \mathrm{MHz}$ do canal de TV em 14 segmentos de 428,57 kHz cada, chamados de segmentos OFDM, como mostra a Figura 1. Esses segmentos podem ser combinados em grupos, formando até 3 camadas hierárquicas, que aqui são chamadas de layers ou camadas $\mathrm{A}$, $\mathrm{B}$ e C, cada qual podendo transmitir o mesmo ou diferentes programas, com diferentes graus de robustez cada.

A codificação de canal, para cada camada, pode ser configurada para diversos graus de robustez, dependendo da exigência de cada aplicação. $O$ segmento localizado no centro do canal é chamado de segmento " 0 " e quando existe transmissão de conteúdo para dispositivos móvel-portáteis, este é o segmento utilizado. 


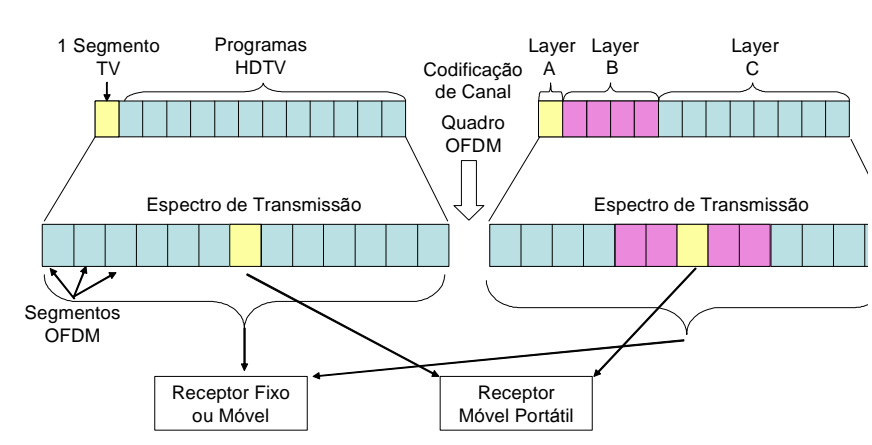

Fig. 1. Conceito do sistema de modulação BST-OFDM utilizado no ISDTV

Os segmentos são numerados do centro para as laterais, mantendo os segmentos pares a direita do zero e os segmentos ímpares a esquerda do zero, como mostra a figura 2.

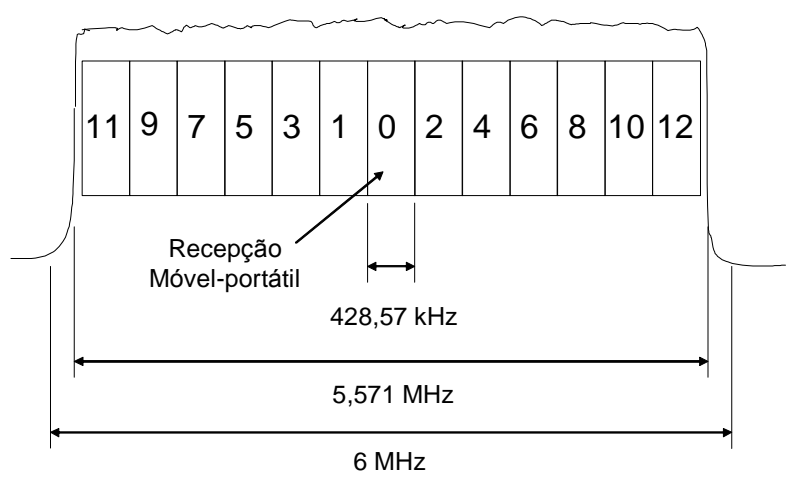

Fig. 2. Enumeração dos segmentos no espectro digital .

Do lado da recepção, cada receptor escolhe a camada, que vai decodificar. Para isso, o transmissor envia além dos dados referentes ao áudio e vídeo codificados, portadoras pilotos que levam informações que permitem ao receptor auto configurar-se, de acordo com os parâmetros que estão sendo utilizados na transmissão. Essas pilotos são chamadas de TMCC (Transmission and Multiplexing Configuration Control).

\section{A. Transmissão}

A figura 3 mostra um diagrama de blocos que compõe o sistema ISDTV. As entradas de dados A, B ou C, codificadas previamente em H.264, são multiplexadas para serem submetidas a um único codificador Reed Solomon [2]. Depois, o feixe de dados é novamente dividido, de acordo com as configurações do codificador convolucional e de modulação, escolhidas previamente para cada segmento OFDM.

Os dados são novamente agrupados em um único bloco, o que significa que se pode ter ao mesmo tempo, em um mesmo canal de televisão, um sinal destinado a receptores fixos, receptores móveis e receptores móvel-portáteis.

Os parâmetros de modulação OFDM, a taxa do codificador convolucional e o tempo do entrelaçador temporal podem ser especificados de forma independente para cada camada.

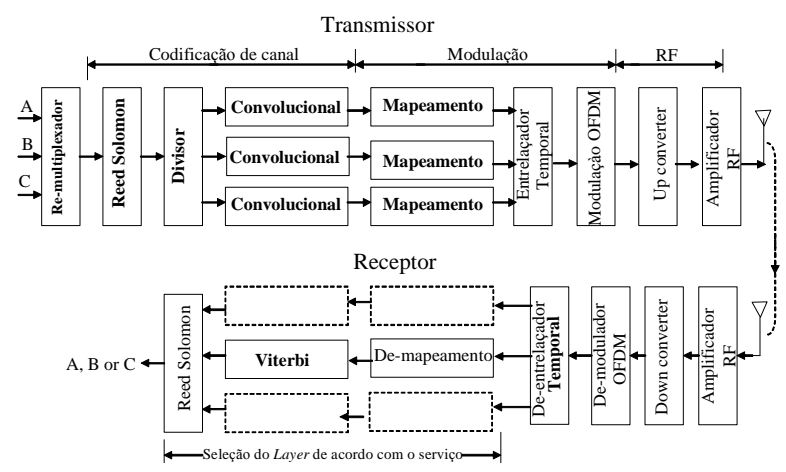

Fig. 3. Diagrama em blocos do sistema ISDTV

O sistema permite a definição de até 3 camadas, sendo que um segmento pode ser utilizado para transmissão móvelportátil, sendo considerado como uma camada. O número de segmentos e os parâmetros podem ser configurados para cada camada, pelo transmissor, de acordo com suas necessidades.

\section{B. Modos de Transmissão}

$\mathrm{O}$ número de portadoras em um símbolo OFDM são identificados como modos de transmissão 1,2 e 3 . O número de portadoras depende do modo utilizado, mas a taxa de bits não é alterada para os três modos. Para cada modo existem diferentes configurações para intervalo de guarda, codificador convolucional e período do entrelaçador temporal, como mostra a tabela 1 [3].

TABELA 1

PARÂMETROS DO SISTEMA ISDTV

\begin{tabular}{|c|c|c|c|c|c|}
\hline $\begin{array}{l}\text { Parâmetros de } \\
\text { configuração }\end{array}$ & \multicolumn{5}{|c|}{ Valores do ISDTV } \\
\hline $\begin{array}{l}\text { Número de } \\
\text { segmentos }\end{array}$ & \multicolumn{5}{|c|}{13} \\
\hline $\begin{array}{l}\text { Segmentação de } \\
\text { Banda (kHz) }\end{array}$ & \multicolumn{5}{|c|}{$6000 / 14=428,57$} \\
\hline $\begin{array}{c}\text { Modos de } \\
\text { transmissão }\end{array}$ & \multicolumn{2}{|l|}{1} & 2 & \multicolumn{2}{|l|}{3} \\
\hline $\begin{array}{c}\text { Banda útil do canal } \\
(\mathrm{MHz})\end{array}$ & \multicolumn{2}{|l|}{5,575} & 5,573 & \multicolumn{2}{|c|}{$5, .752$} \\
\hline $\begin{array}{l}\text { Número de } \\
\text { portadoras por } \\
\text { segmento } \\
\end{array}$ & \multicolumn{2}{|l|}{108} & 216 & \multicolumn{2}{|l|}{432} \\
\hline $\begin{array}{l}\text { Número total de } \\
\text { portadoras }\end{array}$ & \multicolumn{2}{|l|}{1405} & 2809 & \multicolumn{2}{|l|}{5617} \\
\hline $\begin{array}{c}\text { Espaçamento entre } \\
\text { portadoras }\end{array}$ & \multicolumn{2}{|c|}{$3,968 \mathrm{~Hz}$} & $1,984 \mathrm{~Hz}$ & \multicolumn{2}{|c|}{$992 \mathrm{~Hz}$} \\
\hline $\begin{array}{c}\text { Tamanho do símbolo } \\
(\mu \mathrm{s})\end{array}$ & \multicolumn{2}{|l|}{252} & 504 & \multicolumn{2}{|l|}{1008} \\
\hline Modulação & \multicolumn{5}{|c|}{ QPSK, 16QAM, 64QAM } \\
\hline \multirow{4}{*}{$\begin{array}{c}\text { Tamanho do } \\
\text { Intervalo de Guarda } \\
(\Delta) \text { em }(\mu s)\end{array}$} & Modo & $1 / 4$ & $1 / 8$ & 1/16 & $1 / 32$ \\
\hline & 1 & 63 & 31,5 & 15,75 & 7,875 \\
\hline & 2 & 126 & 63 & 31,5 & 15,75 \\
\hline & 3 & 252 & 126 & 63 & 31,5 \\
\hline \multirow{3}{*}{$\begin{array}{c}\text { Tamanho total do } \\
\text { símbolo } \\
T_{S}=\left(T_{U}+\Delta\right) \mathrm{em} \\
(\mu \mathrm{s})\end{array}$} & 1 & 315 & 283,5 & 267,75 & 259,87 \\
\hline & 2 & 628 & 565 & 533,5 & 517,75 \\
\hline & 3 & 1260 & 1134 & 1071 & 1039,5 \\
\hline $\begin{array}{c}\text { Número de símbolo } \\
\text { por quadro }\end{array}$ & \multicolumn{5}{|c|}{204 OFDM símbolos } \\
\hline Codificador Externo & \multicolumn{5}{|c|}{ Reed Solomon $(204,188)$} \\
\hline $\begin{array}{l}\text { Codificador } \\
\text { Convolucional }\end{array}$ & \multicolumn{5}{|c|}{$1 / 2,2 / 3,3 / 4,5 / 6,7 / 8$} \\
\hline
\end{tabular}




\section{Configuração básica da codificação de canal}

As informações transmitidas através do sistema ISDTV consistem de um fluxo de dados, chamado de TS (Transport Stream), que é constituído de uma série de TSP (Transport Stream Packets). A quantidade de pacotes depende do modo $\mathrm{e}$ as configurações de cada segmento OFDM. Esses segmentos são submetidos à codificação de canal, para aumentar sua robustez perante as interferências, como descritos a seguir [4]:

- Reed Solomon, acrescenta 16 bytes de redundância ao TSP, para correção de eventuais erros em rajada;

- Dispersor de Energia, tem como função espalhar seqüências longas de zeros ou uns, que poderiam gerar concentrações de energia, causando interferência intersimbólica.

- Entrelaçador de Bytes, espalha os pacotes do Reed Solomom, aumentando mais a eficiência contra erros de bloco.

- Codificador convolucional, com taxa mãe de $1 / 2$ e opções de puncionamento variável, para ajustar a taxa de correção de erros.

\section{Mapeamento e modulação}

O mapeamento consiste na distribuição dos dados á serem modulados, de acordo com a configuração desejada. A Tabela 2 mostra o número de bits em cada portadora:

TABELA 2

ModulaÇ̃̃o DO FluXo DE BITS

\begin{tabular}{|l|c|c|c|}
\hline Modulação & QPSK & 16QAM & 64QAM \\
\hline Fluxo de Bits & 2 & 4 & 6 \\
\hline
\end{tabular}

Na modulação hierárquica, dois ou três fluxos de dados são modulados e transmitidos ao mesmo tempo. A camada mais robusta utiliza a modulação QPSK, e a camada menos robusta utiliza a modulação 64 QAM.

A codificação de canal e a transmissão hierárquica, permitem que diferentes parâmetros de transmissão sejam configurados e transmitidos simultaneamente no mesmo canal.

Portadoras pilotos (TMCC, AC1 e AC2, SP e CP) são inseridas aos segmentos de dados, no quadro OFDM. Os 13 segmentos são submetidos à IFFT (Inverse Fast Fourier Transform), realizando a modulação OFDM.

Neste ponto, é inserido o intervalo de guarda, que pode ser configurado pelo transmissor. O IG consiste em uma extensão cíclica do símbolo OFDM, como mostra a figura 4, que é inserido no início do símbolo OFDM, o qual não transporta nenhuma informação útil.

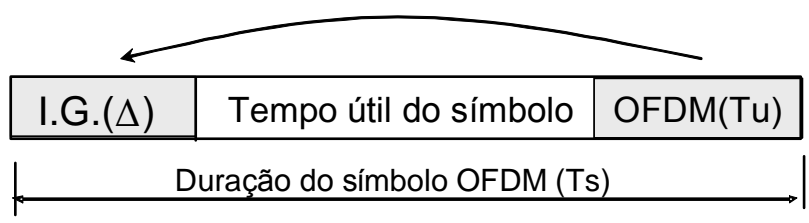

Fig. 4. Inserção do intervalo de guarda (IG)

\section{TESTES DE CAMPO}

Testes de campo foram realizados em outras cidades do mundo [5-6], porém utilizou-se o sistema de modulação adotado naquele país, o ATSC 8-VSB. A metodologia aplicada nos testes do ISDTV aqui apresentada foi baseada na metodologia utilizada nos artigos [5-6], uma vez que os resultados neles apresentados não se aplicam à realidade das cidades brasileiras.

A cidade de São Paulo, em sua área metropolitana, onde foram realizados os testes de campo no Brasil, possui mais de 18 milhões de habitantes. A ocorrência de multipercursos é uma realidade permanente em todas as regiões da cidade, devido à irregularidade do relevo e principalmente aos inúmeros edifícios espalhados pela cidade.

O ruído impulsivo é outra interferência presente em muitos pontos da cidade, uma vez que $50 \%$ da frota de veículos possuem mais de 10 anos de idade. O ruído impulsivo é gerado através do chaveamento de motores que utilizam faísca, como motores automotivos, eletrodomésticos como o secador de cabelo, liquidificador, furadeira etc.

Foi realizado testes de campo para o ISDTV, utilizando um transmissor de UHF sintonizado no canal $24(533 \mathrm{MHz})$, com $1 \mathrm{~kW}$ de potência, utilizando uma antena com ganho de $8 \mathrm{~dB}$, instalada na torre de transmissão da TVA (Grupo Abril), de aproximadamente $100 \mathrm{~m}$ de altura. A torre de transmissão fica localizada no Sumaré, um dos pontos mais altos da cidade de São Paulo.

Utilizando a estação transmissora como centro, foram traçadas 24 radiais espaçadas entre si de $15^{\circ}$, com raios de 2 , 5 e 10 km da estação.

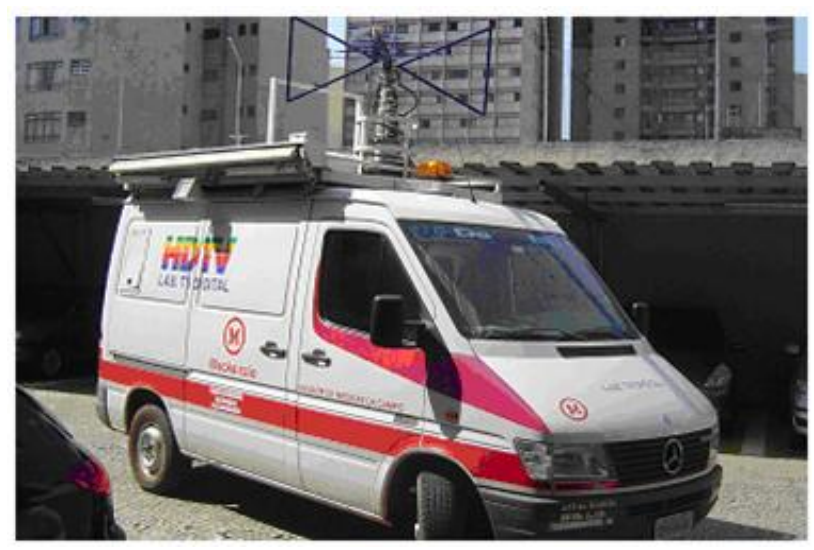

Fig. 5. Unidade móvel de testes de campo

Em cada ponto de recepção, foram testados com a unidade móvel de testes de campo, utilizando uma antena de recepção Schaffner com $18 \mathrm{~dB}$ de ganho, instalada no topo de um mastro retrátil de $10 \mathrm{~m}$ de altura, como mostra a figura 5 .

A etapa de captura dos sinais consiste em receber o sinal com a antena, esse sinal passa por um divisor (Mini-Circuits) e então, uma amostra vai para o analisador de espectros, outra é ligada ao receptor de TV Digital, e uma terceira parte entra no sistema de captura de RF da Eiden.

O primeiro passo é a realização de uma filtragem do sinal, através de um filtro passa-faixas seletivo, ou seja, com ajuste para o canal desejado. Uma vez filtrado, o sinal é então convertido para uma freqüência intermediária $(\mathrm{FI})$ de 44 
MHz e posteriormente passa por um sistema de digitalização, aonde é amostrado a uma freqüência de $21,5244755244 \mathrm{MHz}$ e armazenado em um disco rígido de 100 Gbytes (HD). A figura 6 ilustra o diagrama em blocos do sistema de captura de RF.

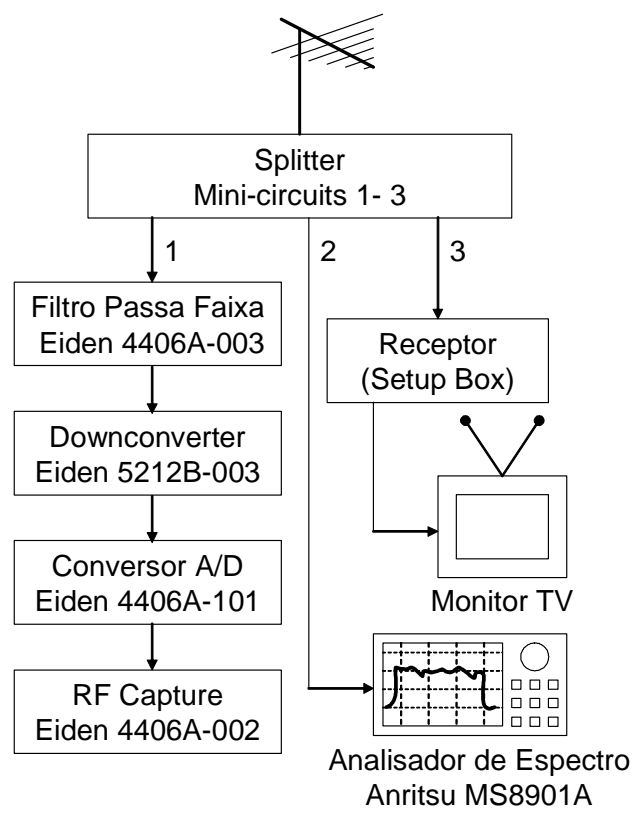

Fig. 6. Diagrama em blocos do sistema de captura de RF

\section{A. Testes realizados em campo}

O modulador foi ajustado para transmitir na configuração conhecida como " $12+1$ ", o que significa que ao mesmo tempo transmitiu-se um sinal HDTV, utilizando 12 segmentos, com modulação 64QAM, modo 3, FEC de 3/4, intervalo de guarda de $1 / 16$ e time interleaving de $0,2 \mathrm{~s}$.

Para o segmento " 0 ", foi utilizada uma modulação mais robusta, uma vez que este segmento foi destinado à recepção móvel-portátil. Utilizou-se o QPSK, com FEC de 2/3 e time interleaving de $0,4 \mathrm{~s}$.

Em cada ponto de recepção, foi analisada a qualidade de imagem do sinal HDTV, do receptor móvel-portátil e de um sinal analógico do canal $32 \mathrm{UHF}$, que é transmitido da mesma torre que foi utilizada para o teste.

Foram anotados os valores da intensidade do sinal recebido, tanto para o sinal analógico como para o sinal digital, com a antena direcionada para a torre de transmissão e posteriormente direcionada para o maior nível de sinal encontrado naquele ponto. Ambos os sinais foram capturados e armazenados utilizando os equipamentos de captura de sinais de RF, para posterior análise em laboratório.

Durante os testes de campo foram levadas em consideração, características do local de recepção, como a presença obstáculos à recepção do sinal, como prédios, torres, casas, árvores, indústrias, tráfego de veículos, linhas de transmissão de energia, efeito Doppler etc, dados que foram utilizados para ajudar nas análises do sinal em laboratório [7].

\section{B. Testes em laboratório}

Os sinais capturados em cada ponto de recepção do teste de campo, foram recuperados e gerados no mesmo canal 24 UHF, utilizando à mesma intensidade de potência verificada em campo.

Utilizando os equipamentos de laboratório foi realizada uma análise do chamado "Delay Profile", que consiste na análise da quantidade de multipercursos presentes no sinal recebido.

$\mathrm{Na}$ seqüência, foi realizado um teste de desempenho da robustez do sinal, injetando-se ruído branco gaussiano até o limiar de percepção, ou seja, quando a imagem começa a apresentar artefatos (blocos) [8]. Foi medido a intensidade do ruído $\mathrm{N}_{\mathrm{i}}(\mathrm{dBm})$ para o canal de $6 \mathrm{MHz}$ e calculado a relação Sinal/Ruído (dB).

\section{ANÁLISE DOS RESULTADOS DOS TESTES}

\section{A. Caracterização dos pontos de recepção}

Para obtermos uma boa caracterização do ambiente de recepção estudado e estabelecer uma relação entre os valores encontrados com as características do meio foram estabelecidos seis critérios:

A: Caracterização pelo tipo de região;

B: Caracterização pelo perfil sócio-econômico;

C: Tráfego de veículos;

D: Altitude dos pontos de recepção;

E: Caracterização da altura das construções próximas,

F: Caracterização da vegetação.

A tabela 3 ilustra a porcentagem dos pontos de recepção para cada critério definido.

\section{TABELA 3}

CLASSIFICAÇÃO DOS PONTOS DE RECEPÇÃO POR CRITÉRIOS DEFINIDOS

\begin{tabular}{|c|c|c|c|c|}
\hline Critérios & Distância & $2 \mathrm{~km}$ & $5 \mathbf{k m}$ & $10 \mathrm{~km}$ \\
\hline A & \multicolumn{4}{|c|}{ Tipo de região } \\
\hline 1 & Urbana Central & $8 \%$ & $21 \%$ & $38 \%$ \\
\hline 2 & Urbana & $92 \%$ & $46 \%$ & $50 \%$ \\
\hline 3 & Periferia & - & $33 \%$ & $12 \%$ \\
\hline 4 & Rural & - & - & - \\
\hline B & \multicolumn{4}{|c|}{ Caracterização Sócio-econômica } \\
\hline 1 & Industrial & - & $4 \%$ & $12 \%$ \\
\hline 2 & Comercial & $30 \%$ & $33 \%$ & $14 \%$ \\
\hline 3 & Residencial & $62 \%$ & $46 \%$ & $67 \%$ \\
\hline 4 & Mista & $8 \%$ & $17 \%$ & $4 \%$ \\
\hline $\mathbf{C}$ & \multicolumn{4}{|c|}{ Tráfego de veículos } \\
\hline 1 & Alto & $17 \%$ & $21 \%$ & $13 \%$ \\
\hline 2 & Médio & $33 \%$ & $42 \%$ & $29 \%$ \\
\hline 3 & Baixo & $50 \%$ & $37 \%$ & $58 \%$ \\
\hline D & \multicolumn{4}{|c|}{ Altitude do ponto de recepção } \\
\hline 1 & Alto & $21 \%$ & $25 \%$ & $33 \%$ \\
\hline 2 & Médio & $21 \%$ & $25 \%$ & $17 \%$ \\
\hline 3 & Baixo & $58 \%$ & $50 \%$ & $50 \%$ \\
\hline $\mathbf{E}$ & \multicolumn{4}{|c|}{ Altura das construções ao redor } \\
\hline 1 & Alto & $17 \%$ & $25 \%$ & $9 \%$ \\
\hline 2 & Médio & $46 \%$ & $29 \%$ & $33 \%$ \\
\hline 3 & Baixo & $37 \%$ & $46 \%$ & $50 \%$ \\
\hline $\mathbf{F}$ & \multicolumn{4}{|c|}{ Vegetação } \\
\hline 1 & Muito Arborizada & $13 \%$ & $9 \%$ & $8 \%$ \\
\hline 2 & Arborizada & $25 \%$ & $29 \%$ & $17 \%$ \\
\hline 3 & Pouco Arborizada & $37 \%$ & $29 \%$ & $33 \%$ \\
\hline 4 & Sem Arborização & $25 \%$ & $33 \%$ & $42 \%$ \\
\hline
\end{tabular}

Comentários gerais:

- Para o raio de $2 \mathrm{~km}$, os locais analisados foram predominantemente na área urbana $(92 \%)$, residencial $(62 \%)$, 
com baixo tráfego de veículos (50\%), localizados em locais baixos $(58 \%)$, cercado de construções médias $(46 \%)$ e com pouca arborização $(37 \%)$.

- Para o raio de $5 \mathrm{~km}$, os locais foram predominantemente na área urbana (46\%), residencial (46\%) mas dividem espaço com atividades comerciais (33\%), com médio tráfego de veículos $(42 \%)$, localizados em locais baixos $(50 \%)$, cercado de construções baixas (46\%) e sem arborização $(33 \%)$.

- Para o raio de $10 \mathrm{~km}$, os locais foram predominantemente na área periférica da cidade $(50 \%)$, residencial $(67 \%)$, com baixo tráfego de veículos $(58 \%)$, localizados em locais baixos $(50 \%)$, cercado de construções baixas (58\%) e sem arborização (42\%). É a região que apresenta maior atividade industrial.

\section{B. Parâmetros avaliados e resultados obtidos}

No geral, os resultados para a recepção fixa de TV Digital mostraram que o receptor comportou-se perfeitamente em todos os pontos analisados. O receptor móvel-portátil, apresentou problemas na imagem em 8 dos 72 pontos de recepção, quando o teste foi realizado dentro do veículo, dos quais, em apenas 2 pontos não foi possível receber o sinal dentro do veículo de testes, porém ao realizar o mesmo teste do lado de fora do veículo, o receptor comportou-se perfeitamente bem.

Os sinais capturados foram analisados em laboratório para a identificação das interferências presentes nos locais de recepção. Foram analisados os seguintes parâmetros:

\section{1) Nivel de sinal recebido}

Para a análise, o nível de sinal recebido foi classificado em quatro categorias:

Sinal forte:

Sinal bom:

$80 \mathrm{~dB} \mu \mathrm{V} / \mathrm{m}$ a $70 \mathrm{~dB} \mu \mathrm{V} / \mathrm{m}$

Sinal fraco: $70 \mathrm{~dB} \mu \mathrm{V} / \mathrm{m}$ a $60 \mathrm{~dB} \mu \mathrm{V} / \mathrm{m}$

Sinal muito fraco: $60 \mathrm{~dB} \mu \mathrm{V} / \mathrm{m}$ a $50 \mathrm{~dB} \mu \mathrm{V} / \mathrm{m}$ abaixo de $50 \mathrm{~dB} \mu \mathrm{V} / \mathrm{m}$

De acordo com estes critérios, foi estabelecida a tabela 4, que ilustra o número de pontos de recepção de acordo com o nível de sinal recebido.

TABELA 4

NíVEL DE SINAL RECEBIDO

\begin{tabular}{|l|c|c|c|}
\hline \multirow{2}{*}{ Nível de Sinal } & \multicolumn{3}{|c|}{ Raio $\mathbf{~ k m}$} \\
\cline { 2 - 4 } & $\mathbf{2}$ & $\mathbf{5}$ & $\mathbf{1 0}$ \\
\hline Forte & 3 & 7 & 0 \\
\hline Bom & 11 & 7 & 3 \\
\hline Fraco & 5 & 3 & 7 \\
\hline Muito Fraco & 5 & 7 & 14 \\
\hline
\end{tabular}

Para o raio de $2 \mathrm{~km}$, nota-se o grande número de locais que apresentam nível de sinal fraco ou muito fraco, mesmo estando localizados próximos a estação transmissora. Este comportamento, pode ser justificado pela tabela 3 , que indicam locais de recepção baixos e envoltos por construções médias.

Para o raio de $5 \mathrm{~km}$, observa-se o aumento do número de locais com nível de sinal muito fraco, o que através da tabela 3, indica ser devido à baixa localização dos pontos de recepção.
Para o raio de $10 \mathrm{~km}$, apresentou resultado esperado, com níveis de sinal fraco e muito fraco predominante (21), uma vez que se aumentou a distância da estação transmissora.

\section{2) Relação Sinal/Ruído na entrada do receptor}

Esta relação foi obtida através da inserção de ruído branco gaussiano $\left(\mathrm{N}_{\mathrm{i}}\right)$ na entrada do receptor, o qual foi lentamente aumentado até alcançar o limiar de recepção $\mathrm{C} / \mathrm{N}$. Quanto menos interferido for o sinal recebido $S_{i}$, mais a relação $S_{i} / N_{i}$ (dB) aproxima-se do valor teórico $\mathrm{C} / \mathrm{N}$. O valor de $\mathrm{C} / \mathrm{N}$ prático, obtido em laboratório foi de $18,11 \mathrm{~dB}$.

Os sinais recebidos foram classificados em três categorias de acordo com a relação obtida. A tabela 5 ilustra os resultados obtidos.

$\begin{array}{ll}\text { Margem alta: } & 18,1 \mathrm{~dB} \leq S_{i} / N_{i} \leq 19,1 \mathrm{~dB} \\ \text { Margem média: } & 19,1 \mathrm{~dB} \leq S_{i} / N_{i} \leq 21,1 \mathrm{~dB} \\ \text { Margem baixa: } & S_{i} / N_{i}>21,1 \mathrm{~dB}\end{array}$

TABELA5

LOCAIS DE RECEPÇ̃̃O X MARGEM

\begin{tabular}{|c|c|c|c|}
\hline Marge & \multicolumn{3}{|c|}{ Raio } \\
\cline { 2 - 4 } $\mathbf{m}$ & $\mathbf{2 k m}$ & $\mathbf{5 k m}$ & $\mathbf{1 0 k m}$ \\
\hline Alta & 15 & 8 & 1 \\
\hline Média & 1 & 6 & 5 \\
\hline Baixa & 8 & 10 & 18 \\
\hline
\end{tabular}

Para o raio de $2 \mathrm{~km}$ foi obtido um resultado inesperado, a grande quantidade de locais com baixa margem, fato que pode ser explicado devido à existência de construções altas e médias ao redor do ponto de recepção. Para os demais raios, os resultados foram os esperados.

\section{3) Multipercurso}

A degradação por multipercursos representa a interferência mais significativa para a recepção de TV Digital, uma vez que $90,5 \%$ da população brasileira recebem o sinal proveniente de uma antena.

Esta análise expressa à quantidade de pré-ecos e pós-ecos, com seus atrasos e níveis de sinal associados. Foi definido o sinal mais forte como sendo o sinal principal. A tabela 6 mostra a quantidade de pré-ecos em cada local de recepção.

TABELA 6

QUANTIDADE DE PRÉ-ECOS

\begin{tabular}{|l|l|l|l|l|l|}
\hline \multicolumn{2}{|c|}{ Raio de 2km } & \multicolumn{2}{c|}{ Raio de 5km } & \multicolumn{2}{c|}{ Raio de10km } \\
\hline $\begin{array}{l}\text { Número } \\
\text { Pré-ecos }\end{array}$ & $\begin{array}{l}\text { Número } \\
\text { de locais }\end{array}$ & $\begin{array}{l}\text { Número } \\
\text { Pré-ecos }\end{array}$ & $\begin{array}{l}\text { Número } \\
\text { de locais }\end{array}$ & $\begin{array}{l}\text { Número } \\
\text { Pré-ecos }\end{array}$ & $\begin{array}{l}\text { Número } \\
\text { de locais }\end{array}$ \\
\hline 1 & 2 & 1 & 2 & 1 & 4 \\
\hline 2 & 3 & 2 & 4 & 2 & 0 \\
\hline 3 & 6 & 3 & 5 & 3 & 1 \\
\hline 4 & 4 & 4 & 2 & 4 & 1 \\
\hline 5 & 3 & 5 & 1 & 5 & 1 \\
\hline 6 & 0 & 6 & 0 & 6 & 2 \\
\hline 7 & 1 & 7 & 0 & 7 & 2 \\
\hline 8 & 1 & 8 & 0 & 8 & 1 \\
\hline 9 & 0 & 9 & 0 & 9 & 0 \\
\hline 10 & 1 & 10 & 0 & 10 & 0 \\
\hline & Total 21 & & Total 14 & & Total 12 \\
\hline
\end{tabular}

Nota-se que para o raio de $2 \mathrm{~km}$, existem apenas 3 pontos de recepção que apresentam apenas pós-ecos.

Para o raio de $5 \mathrm{~km}$, existem 10 pontos de recepção 
apresentando apenas pós-ecos e para o raio de $10 \mathrm{~km}$, existem 12 locais de recepção com apenas pós-ecos.

TABELA 7

ATRASOS PARA O PÓS E PRÉ-ECOS

\begin{tabular}{|c|c|c|c|c|}
\hline \multirow{4}{*}{ Raio } & \multicolumn{2}{|c|}{ Pré-ecos } & \multicolumn{2}{c|}{ Pós-ecos } \\
\cline { 2 - 5 } & $\begin{array}{c}\text { Maior } \\
\text { atraso } \\
(\boldsymbol{\mu s})\end{array}$ & $\begin{array}{c}\text { Média dos } \\
\text { atrasos } \\
(\boldsymbol{\mu} \mathbf{s})\end{array}$ & $\begin{array}{c}\text { Maior } \\
\text { atraso } \\
(\boldsymbol{\mu s})\end{array}$ & $\begin{array}{c}\text { Média dos } \\
\text { atrasos } \\
(\boldsymbol{\mu s})\end{array}$ \\
\hline $\mathbf{2 k m}$ & $-9,97$ & $-2,68$ & $+32,24$ & $+6,67$ \\
\hline $\mathbf{5 k m}$ & $-3,69$ & $-1,68$ & $+55,70$ & $+13,49$ \\
\hline $\mathbf{1 0 k m}$ & $-7,01$ & $-3,05$ & $+34,82$ & $+14,18$ \\
\hline
\end{tabular}

A tabela 7 mostra os valores máximos e a média, encontrados para os atrasos, tanto dos pré-ecos, como dos pós-ecos.

Para o raio de $2 \mathrm{~km}$, a presença de pré-ecos com valores fortes, os quais são mais degradantes para o sinal que os pósecos, e com atrasos maiores que $-9,97 \mu$ s, indicam uma região com muitos obstáculos, como mostrou a tabela 3 , a presença de $63 \%$ de prédios de média e alta atura.

Para o raio de $5 \mathrm{~km}$, quando comparado com o raio de 2 $\mathrm{km}$, nota-se uma queda no número de pré-ecos, de 21 para 14 e o aumento de pós-ecos, de 3 para 10. Os valores de atrasos para os pré-ecos diminuíram, mas por outro lado o valor máximo de atraso para o pós-eco aumentou para $+55,5 \mu \mathrm{s}$.

Para os valores encontrados no raio de $10 \mathrm{~km}$, não apresentaram mudanças significativas em relação ao raio de 5 $\mathrm{km}$, apenas o decréscimo do atraso máximo encontrado para o pós-eco, ficando bastante próximo do valor encontrado para o raio de $2 \mathrm{~km}$.

\section{4) Ruido Impulsivo}

A avaliação do ruído impulsivo foi possível apenas através da observação do sinal analógico de TV, pois o mesmo manifesta-se de forma característica na imagem da TV.

Enquanto realizou-se a medição e análise do sinal analógico do canal $32 \mathrm{UHF}$, foi verificada a presença ou ausência da interferência por ruído impulsivo. A origem destes ruídos foram em $30 \%$ dos casos devido á presença de linhas de transmissão de energia próximo ao ponto de recepção e em $70 \%$ dos casos devido à presença de automóveis, motocicletas ou caminhões transitando próximos ao ponto de recepção.

A tabela 8 mostra a quantidade de locais onde foram encontrados a presença de ruído impulsivo.

TABELA 8

PRESENÇA DE RUíDo IMPULSIVO

\begin{tabular}{|c|c|c|}
\hline Raio & $\begin{array}{c}\text { Número de } \\
\text { pontos de } \\
\text { recepção }\end{array}$ & $\begin{array}{c}\text { Porcentagem } \\
\text { \% }\end{array}$ \\
\hline $\mathbf{2 k m}$ & 7 & $29 \%$ \\
\hline $\mathbf{5 k m}$ & 7 & $29 \%$ \\
\hline $\mathbf{1 0 k m}$ & 10 & $52 \%$ \\
\hline
\end{tabular}

A presença de ruído impulsivo em $52 \%$ dos locais de recepção para o raio de $10 \mathrm{~km}$, indica a presença de muita atividade industrial na região, a grande presença de linhas de transmissão e ao grande tráfego de automóveis.

\section{CONCLUSÕES}

Podem-se concluir através dos testes de campo algumas características da propagação e condições de recepção dos sinais de TV Digital em uma cidade de grande porte como a cidade de São Paulo:

- O sinal de HDTV do sistema ISDTV apresentou uma robustez satisfatória em todos os 72 pontos de recepção selecionados, mesmo na presença de interferências de todos os tipos .

- A recepção do sinal móvel-portátil, mostrou-se satisfatória em 62 pontos de recepção, quando recebido dentro do veículo de testes, o que representa uma degradação ainda maior para o sinal. Este número representa $86 \%$ dos pontos de recepção avaliados.

- Existe uma grande relação entre sinal fraco de recepção $(\leq 60 \mathrm{~dB} \mu \mathrm{V} / \mathrm{m})$ e uma margem de recepção baixa $\left(S_{i} / N_{i}>21,1 \mathrm{~dB}\right)$. Em todos os pontos que apresentaram sinal fraco ou muito fraco (41), 36 apresentaram uma baixa margem.

- A degradação por multipercursos é a principal interferência ao sinal digital. Dos 72 pontos de recepção estudados, em 16 constatou-se a presença de ecos fortes $(0-12 \mathrm{~dB})$ e em 47 pontos, presenciou-se a existência de ecos médios (12- 24 $\mathrm{dB})$.

- Em cerca de $33 \%$ dos locais de recepção avaliados, houve a presença de ruído impulsivo, capaz de degradar o sinal digital de forma significativa, o que demonstra que este tipo de interferência tem relevância nos estudos de performance do sinal digital.

Como trabalho futuro, pretende-se estudar e analisar em campo e em laboratório, as condições de recepção para ambientes de recepção com antena interna, a recepção em dispositivos móveis e a recepção em dispositivos móvel-portáteis em movimento.

\section{REFERÊNCIAS}

[1] Transmission System for digital terrestrial broadcasting, ARIB Standard STB-31, Ver. 1.6 EI, Nov. 2005.

[2] Error correction, data framing, modulation and emission Method for digital terrestrial television broadcasting, ITU-R BT. 1306-3.

[3] M. Uehara, M. Takada, and T. Kuroda, "Transmission scheme for theterrestrial ISDB system," IEEE Trans. on Consumer Electronics, vol.45, no. 1, pp. 101-106, Feb. 1999.

[4] M. Takada and M. Saito, "Transmission System for ISDB-T", Proceedings of the IEEE, Volume 94, Número 1, Jan. 2006.

[5] A. Semmar, J-Y. Chouinard, V.H. Phan, X. Wang, Y. Wu, S. Laflèche, "Digital Broadcasting Television Channel Measurements and Characterization for SIMO Mobile Reception", IEEE Transaction on Broadcasting, Volume 52, Número 4, Dec. 2006.

[6] S. I. Park, Y-T. Lee, J. Y. Lee, S. W. Kim, S. I. Lee, "Field Test Results of the E-VSB System in Korea", IEEE Transaction on Broadcasting, Volume 33, Número 1, Mar. 2007.

[7] G. Bedicks, F. Yamada, Francisco Sukys, C. Dantas, L. T. M. Raunheitte, C. Akamine, "Results of the ISDB-T System Tests as part of Digital TV Study Carried Out in Brazil", IEEE Transaction on Broadcasting, Volume 52, Número 1, Mar. 2006.

[8] F. Yamada, F. Sukys, G. Bedicks Jr, C. Akamine, L.T.M. Rauneitte, C. Dantas, Revista Mackenzie de Engenharia e Computação, Ano 5, Numero 5, São Paulo, 2004.

[9] Y..Wu, E. Pliszka, B. Caron, P. Bouchard, G. Chouinard, "Comparison of Terrestrial DTV Transmission Systems: The ATSC 8 VSB, the DVB-T COFDM, and the ISDB-T BST-OFDM", IEEE Transaction on Broadcasting, Volume 46, Número 2, Jun. 2006. 